\title{
A Hydrometallurgical Process for Cu Recovery from Printed Circuit Boards ${ }^{\dagger}$
}

\author{
Dimitrios Vlasopoulos *, Paschalis Oustadakis (D), Styliani Agatzini-Leonardou, Petros Tsakiridis (D) \\ and Emmanouella Remoundaki (B)
}

check for

updates

Citation: Vlasopoulos, D.; Oustadakis, P.; Agatzini-Leonardou, S.; Tsakiridis, P.; Remoundaki, E. A Hydrometallurgical Process for $\mathrm{Cu}$ Recovery from Printed Circuit Boards. Mater. Proc. 2021, 5, 56. https:// doi.org/10.3390/materproc2021005056

Academic Editor: Anthimos Xenidis

Published: 3 December 2021

Publisher's Note: MDPI stays neutra with regard to jurisdictional claims in published maps and institutional affiliations.

Copyright: (c) 2021 by the authors. Licensee MDPI, Basel, Switzerland. This article is an open access article distributed under the terms and conditions of the Creative Commons Attribution (CC BY) license (https:// creativecommons.org/licenses/by/ $4.0 /)$.
School of Mining and Metallurgical Engineering, National Technical University of Athens, 9, Polytechniou St. 15780 Zografos, Greece; oustadak@metal.ntua.gr (P.O.); agatzi@metal.ntua.gr (S.A.-L.); ptsakiri@central.ntua.gr (P.T.); remound@metal.ntua.gr (E.R.)

* Correspondence: dimvls@metal.ntua.gr; Tel.: +30-210-772-2234

+ Presented at the International Conference on Raw Materials and Circular Economy, Athens, Greece, 5-9 September 2021.

Abstract: The current study presents an effort to develop a sustainable hydrometallurgical process for the recovery of copper from waste printed circuit boards (PCBs) to be applied at local small to medium industrial units. The process aims to separate and recover copper from filter dust produced during the crushing of PCBs using a hammer mill in a recycling facility. Due to the high plastic content in the dust (approximately 30\% w/w), the metal fraction was separated gravimetrically, and the material originated consisted mainly of $\mathrm{Cu}(23.8 \%)$, Fe (17.8\%), Sn (12.7\%), $\mathrm{Pb}(6.3 \%), \mathrm{Zn}(3.4 \%)$, $\mathrm{Al}(3.3 \%), \mathrm{Mn}(1.6 \%)$, and $\mathrm{Ni}(1.5 \%)$. Prior to copper recovery, the dust was leached with $\mathrm{HCl}$ as a pretreatment step. During this step, more than $80 \%$ of iron, zinc, and tin were leached out. The resulting solid consisted mainly of $\mathrm{Cu}(37.6 \%)$ and $\mathrm{Fe}(10.7 \%)$, leading to a copper enrichment of around $60 \%$ in the powder. The leaching of copper was conducted in a two-step process using $\mathrm{H}_{2} \mathrm{SO}_{4}$ as a leaching agent with the addition of $\mathrm{H}_{2} \mathrm{O}_{2}$ as an oxidizing agent. The experimental conditions had low energy requirements (no heating or agitation needed). The leaching of $\mathrm{Cu}$ reached $98 \%$. Despite the pretreatment step, the concentration of other metals $(\mathrm{Fe}, \mathrm{Zn}, \mathrm{Ni})$ in the pregnant solution was too high to proceed to electrowining. Therefore, the organic solvent ACORGA M5640 was selected for the extraction of copper from the pregnant solution. The extraction was conducted in two stages at $\mathrm{pH}$ equilibrium 1.5, and the loaded organic phase was stripped with $\mathrm{HCl}$ in two steps. The strip liquor was suitable for electrowinning.

Keywords: copper; leaching; hydrometallurgy; recycling; PCBs

\section{Introduction}

In the last decades, the amount of electric devices in the market has increased. Thus, the demand of raw materials in electric devices has also increased [1]. However, the ores used by the traditional mining industry are reaching their limits, and the struggle to reach the demands in the future will increase day by day [2].

Wasted printed circuit boards (PCBs) contain the highest concentrations of base and precious metals [3]. Hence, it is of great importance for them to be recycled. At present, the main route for the recycling of electronic scrap is based mainly on physical and pyrometallurgical methods. Although, pyrometallurgy has high metal recovery and is a well-known technology, the high energy needs and the environmental restrictions make its processes unsustainable [4]. On the other hand, hydrometallurgical methods are not energy intensive and do not produce gaseous emissions, and for these reasons they are mainly considered sustainable compared to pyrometallurgical methods [5].

The European Union's annual copper demand is around 4 million tons and rising [6]. In 2016, almost $40 \%$ of copper needed was imported [6]. Recovering copper from e-waste could decrease the amount of imports. The percentage of copper contained in PCBs 
$(10-20 \%)$ remains the highest among all metals, much higher than in natural ores [7]. A particular interest is expressed by e-waste recycling companies for pure metal recovery from e-wastes. Only sustainable metallurgical processes for metal recovery from e-wastes can be scaled up by local small to medium industrial units [8].

This study, part of the HYDROPCB project (Development of a hydrometallurgical process for metal recovery from Printed Circuit Boards in pilot scheme: A zero waste process), presents the results obtained in an effort to selectively recover copper from filter dust, produced during the crushing of PCBs in a hammer mill at a local recycling facility (ECORESET SA).

\section{Materials and Methods}

In the present research, a dust sample was provided by a local recycling facility.

\subsection{Solid Characterization and Pretreatment Leaching}

The characterization of the dust and the solid products was performed by dissolution after eutectic fusion at $1000{ }^{\circ} \mathrm{C}$. The dust composition in plastic material was determined by Thermogravimetric Analysis (TGA) and Differential Scanning Calorimetry (DSC). The leaching solutions were analyzed by Atomic Absorption Spectrometry (AAS). The solids were analyzed by X-ray Diffraction (XRD) and Scanning Electron Microscopy (SEM).

The dust was subjected to treatment in a shaking table and divided in two fractions, a metallic and a non-metallic.

Prior to leaching for the extraction of copper, the metallic part of the initial dust was subjected to leaching with $6 \mathrm{M} \mathrm{HCl}$ (pretreatment leaching) in order to remove other metals and enrich the fraction in copper. The resulted leached residue was the raw material for copper recovery.

\subsection{Leaching of Copper}

The copper dust was leached with $\mathrm{H}_{2} \mathrm{SO}_{4}$, and $\mathrm{H}_{2} \mathrm{O}_{2}$ was used as the oxidizing agent $(\mathrm{OA})$. The effect of various process factors on $\mathrm{Cu}$ recovery was investigated. The factors studied were the $\mathrm{S} / \mathrm{L}$ ratio $(0.05 \mathrm{~g} / \mathrm{mL}, 0.1 \mathrm{~g} / \mathrm{mL}$, and $0.2 \mathrm{~g} / \mathrm{mL})$, the leaching agent concentration $(1 \mathrm{M}, 2 \mathrm{M}$, and $3 \mathrm{M})$, and the oxidizing agent concentration $\left(1 \mathrm{~mL} / \mathrm{O} \cdot \mathrm{A} / \mathrm{g}_{\text {solid }}\right.$, $2 \mathrm{~mL}$ O.A. $/ \mathrm{g}_{\text {solid }}, 4 \mathrm{~mL} \cdot \mathrm{A} \cdot / \mathrm{g}_{\text {solid }}$, and $6 \mathrm{~mL}$.A $\left.\cdot / \mathrm{g}_{\text {solid }}\right)$. The residence time for all the experiments was $4 \mathrm{~h}$. The optimum conditions were then determined, and a solution was prepared by leaching the copper dust at these conditions

\subsection{Extraction and Stripping of Copper}

The resulting solution was then used to study the extraction of copper using solvent extraction with ACORGA M5640. The effect of the $\mathrm{pH}$ on the extraction efficiency was investigated. A McCabe-Thiele extraction diagram was plotted. The loaded organic phase was stripped by $\mathrm{HCl}$. The effect of the $\mathrm{HCl}$ concentration on the stripping efficiency was investigated. A McCabe-Thiele stripping diagram was plotted.

\section{Results}

\subsection{Pretreatment Leaching}

The chemical composition of the PCB dust and the metallic fraction after the physical separation in the shaking table are presented in Table 1 . The non-metallic fraction in the initial dust was $30 \% w / w$. During the pretreatment step, less than $0.3 \%$ of copper was leached. Thus, the solid was enriched in copper. 
Table 1. Chemical composition of the dust before and after separation and the pretreatment step.

\begin{tabular}{cccc}
\hline Metal & Initial Dust (\% wt.) & $\begin{array}{c}\text { Metallic Fraction after } \\
\text { Separation (\%wt.) }\end{array}$ & $\begin{array}{c}\text { Solid Product after Pretreatment } \\
\text { Leaching (\%wt.) }\end{array}$ \\
\hline $\mathrm{Sn}$ & 5.01 & 12.74 & 1.30 \\
$\mathrm{Cu}$ & 5.19 & 23.86 & 37.60 \\
$\mathrm{Fe}$ & 8.17 & 17.84 & 10.67 \\
$\mathrm{Zn}$ & 1.90 & 3.36 & 1.68 \\
$\mathrm{Ni}$ & 0.76 & 1.48 & 1.77 \\
$\mathrm{~Pb}$ & 1.53 & 6.28 & 7.45 \\
$\mathrm{Al}$ & 3.18 & 3.29 & 1.04 \\
$\mathrm{Total}$ & 26.50 & 68.85 & 61.51 \\
\hline
\end{tabular}

\subsection{Leaching of Copper}

The effect of the leaching agent concentration on Cu recovery is given in Table 2.

Table 2. $\mathrm{Cu}$ recovery after two-step leaching of the copper dust in $1 \mathrm{M}, 2 \mathrm{M}$, and $4 \mathrm{M} \mathrm{H}_{2} \mathrm{SO}_{4}$ in an $\mathrm{S} / \mathrm{L}$ ratio of $0.1 \mathrm{~g} / \mathrm{mL}$ and $1 \mathrm{~mL} \mathrm{H}_{2} \mathrm{O}_{2}(30 \% w / w) / \mathrm{g}$ of copper dust.

\begin{tabular}{cc}
\hline $\mathrm{H}_{2} \mathrm{SO}_{4}$ Concentration & Cu Leaching Efficiency \% \\
\hline $\mathbf{1} \mathbf{M}$ & 62.4 \\
$\mathbf{2}$ & 66.0 \\
$4 \mathbf{M}$ & 45.6 \\
\hline
\end{tabular}

It was concluded that $2 \mathrm{M}$ was the optimum $\mathrm{H}_{2} \mathrm{SO}_{4}$ concentration. The effect of the $\mathrm{S} / \mathrm{L}$ ratio and the $\mathrm{H}_{2} \mathrm{O}_{2}$ concentration on leaching efficiency at $2 \mathrm{M} \mathrm{H}_{2} \mathrm{SO}_{4}$ was then studied, and the results are shown in Figure $1 \mathrm{a}$ and $1 \mathrm{~b}$, respectively.



(a)

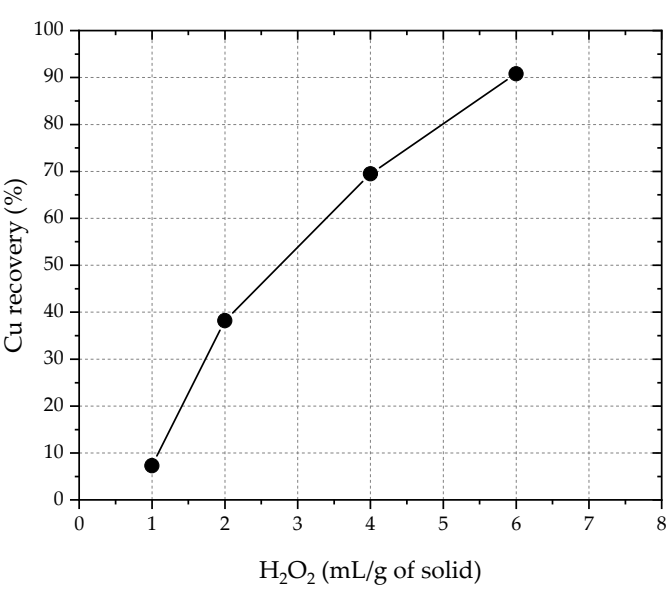

(b)

Figure 1. (a) Effect of the $\mathrm{S} / \mathrm{L}$ ratio on Cu recovery, using $2 \mathrm{M} \mathrm{H}_{2} \mathrm{SO}_{4}$ and $1 \mathrm{~mL} \mathrm{H}_{2} \mathrm{O}_{2}(30 \% w / w) / g$ of copper dust. (b) Effect of the $\mathrm{H}_{2} \mathrm{O}_{2}$ concentration ( $\mathrm{mL}$ of oxidant/g of dust) on Cu recovery, using $2 \mathrm{M} \mathrm{H}_{2} \mathrm{SO}_{4}$ and an S/L ratio of $0.1 \mathrm{~g} / \mathrm{mL}$.

Based on the results, the relatively optimum conditions for $\mathrm{Cu}$ were determined as follows:

- A total of $2 \mathrm{M} \mathrm{H}_{2} \mathrm{SO}_{4}$ as leaching agent;

- A total of $3 \mathrm{~mL} / \mathrm{g} \mathrm{H}_{2} \mathrm{O}_{2}(30 \% w / w)$ as oxidizing agent;

- $\quad$ An $\mathrm{S} / \mathrm{L}$ ratio of $0.1 \mathrm{~g} / \mathrm{mL}$;

- Two stages;

- $\quad$ Residence time of $4 \mathrm{~h}$;

- No agitation. 
A two-stage leaching test of the copper dust was carried out at these relatively optimum conditions. The results are shown in Table 3.

Table 3. Cu recovery during a two-stage leaching test.

\begin{tabular}{cc}
\hline Leaching Stage & Cu Recovery \% \\
\hline $\mathbf{1}$ & 34.4 \\
$\mathbf{2}$ & 63.7 \\
Total & 98.1 \\
\hline
\end{tabular}

\subsection{Extraction and Stripping of Copper}

The copper solution produced at the optimum conditions of leaching was subjected to purification by chemical precipitation of the impurity metals contained in order to be further treated by solvent extraction. The purification was conducted at $\mathrm{pH} 3.0$ by the addition of $5 \mathrm{M} \mathrm{NaOH}$. Table 4 gives the analysis of the pregnant solution before and after purification.

Table 4. Analysis of the pregnant solution before and after purification at $\mathrm{pH}$ 3.0.

\begin{tabular}{ccc}
\hline Metal & $\begin{array}{c}\text { Concentration before Purification } \\
(\mathbf{g} / \mathbf{L})\end{array}$ & $\begin{array}{c}\text { Concentration after Purification } \\
(\mathbf{g} / \mathbf{L})\end{array}$ \\
& 18.8 & 13.8 \\
$\mathrm{Cu}$ & 2.6 & 0.44 \\
$\mathrm{Fe}$ & 1.0 & 0.32 \\
$\mathrm{Zn}$ & 1.17 & 0.40 \\
$\mathrm{Ni}$ & & \\
\hline
\end{tabular}

A number of solvent extraction tests were conducted in various $\mathrm{pH}$ values in order to determine the optimum extraction $\mathrm{pH}$, which was determined to be 1.5. The analysis of the raffinate after solvent extraction in one stage with ACORGA M5640 ( $30 \% v / v$ in kerosene), at $\mathrm{pH} 1.5$, at an A/O ratio of 1:1, and a contact time of $5 \mathrm{~min}$ is shown in Table 5.

Table 5. Analysis of the pregnant solution after solvent extraction with ACORGA M5640 in one stage.

\begin{tabular}{ccccc}
\hline pH & $\begin{array}{c}\mathrm{Cu} \\
(\mathrm{mg} / \mathrm{L})\end{array}$ & $\begin{array}{c}\mathrm{Fe} \\
(\mathrm{mg} / \mathrm{L})\end{array}$ & $\begin{array}{c}\mathrm{Zn} \\
(\mathbf{m g} / \mathrm{L})\end{array}$ & $\begin{array}{c}\mathrm{Ni} \\
(\mathbf{m g} / \mathrm{L})\end{array}$ \\
\hline 1.5 & 1460 & 405 & 305 & 375 \\
\hline
\end{tabular}

Copper was stripped off the loaded organic phase in the stripped liquor with $2 \mathrm{M}$ $\mathrm{HCl}$, and its analysis is shown in Table 6.

Table 6. Analysis of the stripped liquor in one step.

\begin{tabular}{ccccc}
\hline $\begin{array}{c}\mathrm{HCl} \\
(\mathrm{M})\end{array}$ & $\begin{array}{c}\mathrm{Cu} \\
(\mathrm{mg} / \mathrm{L})\end{array}$ & $\begin{array}{c}\mathrm{Fe} \\
(\mathbf{m g} / \mathrm{L})\end{array}$ & $\begin{array}{c}\mathrm{Zn} \\
(\mathbf{m g} / \mathrm{L})\end{array}$ & $\begin{array}{c}\mathbf{N i} \\
(\mathbf{m g} / \mathrm{L})\end{array}$ \\
\hline 2 & 7400 & 0.16 & 0.06 & 0.01 \\
\hline
\end{tabular}

The analysis shows that the stripped liquor is suitable for electrowinning, as it contained mainly copper. All other metals had a concentration of less than $0.2 \mathrm{mg} / \mathrm{L}$.

A McCabe-Thiele diagram for the extraction of copper from the pregnant solution was plotted for the equilibrium $\mathrm{pH} 1.5$ (Figure 2a). For an A/O ratio of 1:1, copper can be extracted from the pregnant solution, quantitatively, in two stages.

A McCabe-Thiele stripping diagram was plotted for $2 \mathrm{M} \mathrm{HCl}$ as stripping solution (Figure 2b). For an A/O ratio of 1:1, copper can be stripped off the loaded organic phase, quantitatively, in two stages. 




(a)

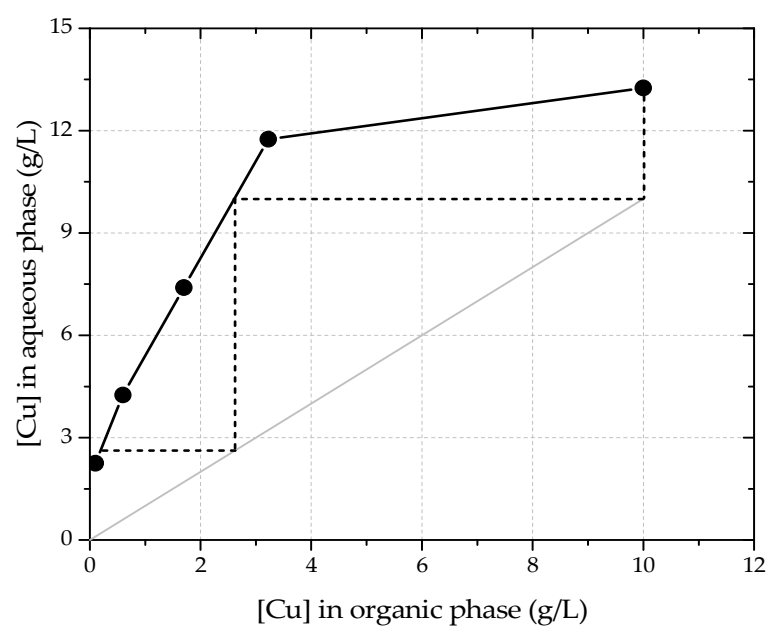

(b)

Figure 2. (a) McCabe-Thiele extraction diagram at equilibrium $\mathrm{pH}$ 1.5. The A/O ratio for the operation line is 1:1. (b) McCabe-Thiele stripping diagram with $2 \mathrm{M} \mathrm{HCl}$. The A/O ratio for the operation line is 1:1.

\section{Conclusions}

The conclusions of this study are:

- The PCB metallic fraction, after the removal of the plastic material, is a remarkable copper resource as its copper content exceeds $20 \%$ and can be treated hydrometallurgically.

- More than $98 \%$ of copper was recovered from the dust by oxidative leaching in two stages, using $2 \mathrm{M} \mathrm{H}_{2} \mathrm{SO}_{4}, 3 \mathrm{~mL} \mathrm{H} \mathrm{O}_{2}(30 \% w / w) / \mathrm{g}$ dust, and a solid/liquid ratio of $0.1 \mathrm{~g} / \mathrm{mL}$ of dust.

- $\quad$ The optimum $\mathrm{pH}$ for the copper solvent extraction with ACORGA M5640 was 1.5.

- Copper was extracted quantitatively from the pregnant solution in two stages by ACORGA M5640 organic reagent at equilibrium $\mathrm{pH} 1.5$ and an A/O ratio of 1:1.

- Copper was stripped off the loaded organic phase quantitatively in two stages by $2 \mathrm{M}$ $\mathrm{HCl}$ and at an $\mathrm{A} / \mathrm{O}$ ratio of 1:1.

- The concentration of copper in the stripped liquor was $7.4 \mathrm{~g} / \mathrm{L}$, with all other impurities being less than $0.2 \mathrm{mg} / \mathrm{L}$, thus allowing copper electrowinning.

Funding: This research has been co-financed by the European Regional Development Fund of the European Union and Greek national funds through the Operational Program Competitiveness, Entrepreneurship and Innovation, under the call RESEARCH-CREATE-INNOVATE (project code: T1EDK-00219).

Acknowledgments: The authors wish to thank ECORESET S.A. for providing the PCB dust sample.

\section{References}

1. Robinson, B.H. E-waste: An assessment of global production and environmental impacts. Sci. Total Environ. 2009, 408, 183-191. [CrossRef] [PubMed]

2. Watari, T.; Nansai, K.; Nakajima, K. Major metals demand, supply, and environmental impacts to 2100: A critical review. Resour. Conserv. Recy. 2021, 164, 105-107. [CrossRef]

3. Khaliq, A.; Rhamdhani, M.A.; Brooks, G.; Masood, S. Metal extraction processes for electronic waste and existing industrial routes: A review and Australian perspective. Resources 2014, 3, 152-179. [CrossRef]

4. Cui, J.; Zhang, L. Metallurgical recovery of metals from electronic waste: A review. J. Hazard. Mater. 2008, 158, 228-256. [CrossRef] [PubMed]

5. Andrews, D.; Raychaudhuri, A.; Frias, A. Environmentally sound technologies for recycling secondary lead. J. Power Sources 2000, 88, 124-129. [CrossRef]

6. European Copper Institute. Available online: www.copperalliance.eu (accessed on 25 May 2021). 
7. Hageluken, C. Improving Metal Returns and eco-efficiency in electronics recycling-A holistic approach for interface optimization between pre-processing and integrated metals smelting and refining. In Proceedings of the IEEE International Symposium on Electronics and the Environment, San Francisco, CA, USA, 8-11 May 2006.

8. Biswajit, D.; Chowdhury, R.; Ghosh, S.K. Sustainability of metal recovery from E-waste. Front. Environ. Sci. Eng. 2018, 12, 2. 